\title{
Legalizing physician-assisted suicide and/or euthanasia: Pragmatic implications
}

\author{
PETER HUDSON, R.N., PH.D., ${ }^{1,2,3}$ ROSALIE HUDSON, R.N., PH.D., 4 \\ JENNIFER PHILIP, PH.D., F.A.C.H.P.M., ${ }^{1,3}$ MARK BOUGHEY, M.PH., ${ }^{1,3}$ BRIAN KELLY, PH.D., F.R.A.N.Z.C.P., ${ }^{5}$ \\ AND CEES HERTOGH, PH.D., M.D. ${ }^{6,7}$ \\ ${ }^{1}$ Centre for Palliative Care, St. Vincent's Hospital, Melbourne Australia \\ ${ }^{2}$ Queen's University, Belfast, Northern Ireland, United Kingdom \\ ${ }^{3}$ University of Melbourne, Melbourne, Victoria, Australia \\ ${ }^{4}$ Department of Nursing, University of Melbourne \\ ${ }^{5}$ School of Medicine and Public Health, Faculty of Health, University of Newcastle, New South Wales, Australia \\ ${ }^{6}$ Department of General Practice and Elderly Care Medicine, EMGO Institute for Health and Care Research, \\ Amsterdam, The Netherlands \\ ${ }^{7}$ Department of General Practice and Elderly Care Medicine, VU University Medical Centre, Amsterdam, \\ The Netherlands \\ (RECEIVED September 9, 2014; ACCEPTED December 21, 2014)
}

\begin{abstract}
Objective: Despite the availability of palliative care in many countries, legalization of euthanasia and physician-assisted suicide (EAS) continues to be debated-particularly around ethical and legal issues-and the surrounding controversy shows no signs of abating. Responding to EAS requests is considered one of the most difficult healthcare responsibilities. In the present paper, we highlight some of the less frequently discussed practical implications for palliative care provision if EAS were to be legalized. Our aim was not to take an explicit antiEAS stance or expand on findings from systematic reviews or philosophical and ethico-legal treatises, but rather to offer clinical perspectives and the potential pragmatic implications of legalized EAS for palliative care provision, patients and families, healthcare professionals, and the broader community.

Method: We provide insights from our multidisciplinary clinical experience, coupled with those from various jurisdictions where EAS is, or has been, legalized.

Results: We believe that these issues, many of which are encountered at the bedside, must be considered in detail so that the pragmatic implications of EAS can be comprehensively considered.

Significance of Results: Increased resources and effort must be directed toward training, research, community engagement, and ensuring adequate resourcing for palliative care before further consideration is given to allocating resources for legalizing euthanasia and physicianassisted suicide.
\end{abstract}

KEYWORDS: Euthanasia, Physician-assisted suicide, Legalization

\section{INTRODUCTION}

Palliative care offered by a multidisciplinary team is intended to improve the quality of life of patients di-

Address correspondence and reprint requests to: Peter Hudson, Centre for Palliative Care, St. Vincent's Hospital, P.O Box 2900, Melbourne, Australia. E-Mail: phudson@unimelb.edu.au agnosed with an incurable life-limiting illness and their families (Palliative Care Australia, 2005). Open discussion of death's inevitability and acknowledgment that dying is a normal process are key elements of palliative care (World Health Organization, 2002; Palliative Care Australia, 2011a,b). Despite the availability of palliative care within Australia and in many other countries, legalization of 
euthanasia and physician-assisted suicide (EAS) (Dees et al., 2013) continues to be debated (Macleod et al., 2012), particularly around ethical and legal issues (Pellegrino, 2001), a controversy that shows no sign of diminishing (Hendry et al., 2013).

Palliative care cannot fully relieve all people's suffering, and even with the availability of optimal palliative care it is likely that EAS will continue to be sought by some. We seek to highlight some of the less frequently discussed practical implications for palliative care provision and, more broadly, if EAS were to be legalized in Australia. Our arguments and concerns are based on our collective longstanding clinical experience in palliative care medicine, nursing, specialist psychiatry, and geriatrics, and are considered in the context of published insights from various jurisdictions where EAS is legalized and/or tolerated. Our aim is not to take an explicit anti-EAS stance or expand on findings from systematic reviews or philosophical and ethico-legal treatises (Hendry et al., 2013), but rather to offer clinical perspectives and the potential implications of legalized EAS for patients and families, healthcare professionals, and the broader community.

Responding to EAS requests is considered to be one of the most difficult healthcare responsibilities (Dees et al., 2013). Our thesis is that what is intended in legislation to assist a small group of patients may have a more generalized effect on the way end-of-life care is perceived. It will inevitably have pragmatic consequences for palliative care and for healthcare more broadly, ones that have hitherto not been comprehensively considered. Pertinent points are illustrated by brief vignettes.

\section{Implications for Patients and Families}

A number of serious misconceptions are evident regarding the goal and intention of the treatments employed in palliative care. In clinical practice, the belief by patients and relatives that some medications, particularly opioids, are used for hastening death rather than for symptom relief, is frequently encountered (Reid et al., 2008). This mistaken belief is also held by some clinicians less experienced in palliative care (Kwon, 2014). Hence, they may view essential end-of-life symptom management, such as opioids for pain relief, as euthanasia (White et al., 2011), exemplified by the following cases:

In a busy hospital palliative care consultative service, there are daily discussions with patients, often elderly, who are fearful of opioids precipitating their death. On this day, an 82-year-old Greek man with newly diagnosed pancreatic cancer is concerned that the low dose of morphine pre- scribed for pain relief will result in his premature death. A great deal of time and reassurance is given, yet still he remains uneasy and reluctant to take effective analgesia.

The wife of a man with respiratory distress from end-stage chronic obstructive pulmonary disease refuses to let her husband have low-dose oral morphine despite him finding it effective the previous day. She explains that a strong Catholic faith precludes him from having euthanasia.

In a context where EAS is condoned, such fear may increase, and the possibility of forgoing analgesia or other symptom relief would be a potential outcome. Though evidence of this is not apparent where EAS is currently tolerated, the impact should continue to be evaluated. Further, the consequences for the doctor/patient relationship should be carefully monitored; it is possible that the trust inherent in this relationship, particularly in end-of-life care (Steinhauser et al., 2000), may be eroded were physicians permitted by law to offer EAS (White \& Willmott, 2012). We strongly advocate further research in this area.

It is also apparent that patients and their relatives have many misconceptions about what dying involves, and this may influence their views regarding EAS. It seems that the overwhelming majority of media attention about the end of life and terminal illness focuses on conceptions that dying is inherently painful, undignified, and traumatic for both patient and family. In reality, this is simply untrue. We have witnessed thousands of deaths where, in the lead-up, the patient has been comfortable, able to communicate their wishes, and say farewells, and families have commented on how peaceful the death was. In addition, many family carers seem to derive personal growth and identify positive aspects associated with their caregiving role (Hudson, 2004; Wong et al., 2009). Although as palliative care specialists we cannot claim that every patient can be guaranteed a peaceful death, a more nuanced view is strongly needed; otherwise, misconceptions about dying may fuel people's wish to secure control over the circumstances of their death. The oftenmisplaced view that intensification of treatment is inevitable as death nears, involving intrusive medical intervention and machinery, seems widespread among the broader community (Rubeli, 2012). Patients clearly indicate that factors such as clear communication, symptom control, and time to prepare for death are important at the end of life, rather than a focus upon intensive life prolongation (Steinhauser et al., 2000).

The current misconception of dying, as occurring within a highly technological environment and 
inevitably taken out of the patients' hands, leads some to advocate for EAS:

An elderly man, [with] a prominent local identity, was admitted to hospital with heart failure. He refused all medications and asked for euthanasia. After exploration of his concerns, he revealed that he did not wish to have his life prolonged, did not wish to die in hospital, nor in intensive care. He agreed that symptom control measures were consistent with his wishes, and following institution of diuretics and rate-control drugs, as well as community supports, he returned home. There he held a "wake" party, and died three weeks later with his family and friends around.

The development of advance-care directives and involvement of family in discussion around wishes for treatment may substantially assist in addressing concerns regarding a "medicalized" death over which the patient has no control (Detering et al., 2010; Mack et al., 2012). Some fear losing control of circumstances, others may fear being alone in facing death, and some are concerned about dependence on others (Kelly \& Varghese, 1996; Oldham et al., 2011). Euthanasia may be seen as a solution to being a burden on the family (George et al., 2005; Pereira, 2011), exemplified in this scenario:

An elderly woman was afraid of being a burden to her adult daughter, knowing that her daughter would need to take leave from work to care for her. This fear led her to express a desire to "end it all."

While one patient may focus on the perceived inconvenience to her family (which may be very considerable, though it may also be willingly shouldered) and choose to seek a hastened death or forego lifesustaining treatment as an alternative, another may acknowledge the potential benefits that may emerge within a relationship that involves permission to care and permission to be cared for. Such a response recognizes that caring may provide mutual benefits within a relationship and can, for some, enhance growth for those involved. Still others may respond to the burden of care as a shared response and seek additional support. For these patients, knowing that their family can receive education, information, respite, and other practical assistance may lessen the perception of burden (Hudson et al., 2012). For many families, these opportunities for support are not currently available, and the burden is not always ameliorated (Hudson \& Payne, 2011).

In summary, there are many misconceptions and misguided fears about the end of life. Fear can be a bad counselor (Hertogh et al., 2007); accordingly, resources should be directed toward rectifying misunderstandings among health professionals and the broader community. Fear is also associated with inaccurate perceptions of what palliative care is and what it can offer. In the words of one palliative care pioneer, "there are currently more than fifty different definitions of palliative care; no wonder that the public and healthcare professionals are confused" (Doyle, 2003). We acknowledge that, if comprehensively outlined and fully explained in an unbiased manner, then implementation of EAS may assist in clarifying the boundaries of palliative care.

\section{Implications for Healthcare Professionals}

\section{Meeting the Criteria for EAS}

In some jurisdictions where EAS is legal or tolerated, a necessary criterion is the presence of unbearable suffering. How "unbearable" is defined and what its relationship may be to the skills of the person tasked with ameliorating the suffering deserves consideration. According to the Dutch law on EAS, unbearable suffering is not a technical term, nor should it be medicalized. "Unbearable" refers to a subjective evaluation by the patient, given their prospects, their views on a good death, and consideration of the options that are available to them as alternatives to EAS. It is the responsibility of the physician to discuss all these options (including palliative care) with the patient before arriving at the joint conclusion that there are, from the patient's perspective, no feasible alternatives (Hertogh, de Boer et al. 2007).

We acknowledge that physicians' skills in caring for those with advanced illness vary greatly. Some doctors readily engage in discussions around treatment limits and end-of- life care; they have knowledge of, and interest in, providing expert symptom relief and are skilled at exploring complex issues of psychological, social, and spiritual importance for a person facing the end of life. Others feel less confident and comfortable doing so. Studies have found that some physicians tend to focus on the physical aspects of end-of-life care, while patients and families want a broader spiritual, psychological, and social focus drawn from their life experience (Steinhauser et al., 2000; Kelly et al., 2004). The lack of willingness to engage around these concerns, and perhaps the lack of ability to determine the limits of their own skills, may lead some doctors to suggest that there is nothing that can be done. That is, the physician who is inexperienced with pain and symptom management or uncomfortable with discussing existential concerns may more readily agree that the suffering is "unbearable" or arrive at the conclusion that the patient's symptoms are refractory (Kelly 
et al., 2004). In such circumstances, EAS may appear to be the logical option for both patient and doctor. Yet the same suffering may be effectively addressed by the care of a more experienced colleague:

An elderly patient with advanced cervical cancer was frequently incontinent of feces, due to a fistula between her bowel and vagina. She was deeply ashamed, remained at home and shunned visitors because of the odor and difficulty managing incontinence pads. She sought euthanasia from her doctor, who agreed her life was miserable, and began preparations. In the course of these "preparations," the patient was reviewed by a physician who suggested she consider surgical diversion of her bowel via a colostomy and additional psychosocial supports. After extensive discussion, she proceeded to surgery, learned how to manage stoma bags, and had three more months of life at home, when she reengaged with her family and friends. She died of metastatic disease, no longer incontinent.

Decision making may also be compounded by the doctor's own response to suffering, their capacity to tolerate patients' suffering, and their ability to identify when psychological intervention is needed (Kelly et al., 2004). In Oregon, where unrelieved suffering is not a requirement for EAS, those who assist with the patient's request are not required to have advanced clinical expertise in relieving physical or psychological suffering (Hendin \& Foley, 2008). In such instances, the underlying reasons for the request can be overlooked. Even when psychiatrists are involved, their capacity to confidently assess the existence and role of mental illness in EAS has been questioned (Levene \& Parker, 2011). Assessing mental capacity, a common requirement for jurisdictions where euthanasia and physician-assisted suicide are legalized, can also be problematic for doctors (Price et al., 2014).

Recognition of the final phase of life is notoriously difficult to diagnose, and errors in prognostication are common (Glare et al., 2008). In some instances where EAS is legalized, there is a requirement that the patient be expected to die within six months (Oregon Health Authority, 2014a); however, estimations of life expectancy are typically erroneous (Frost et al., 2014), particularly in the context of such chronic diseases as dementia (Volicer, 2008). It is also common in EAS legislation to ensure that a second medical opinion be obtained (Frost et al., 2014). Currently in Australia and many other countries, the overwhelming majority of patients with a life-threatening illness are not seen by a specialist palliative care physician (Johnson et al., 2011; Davies et al., 2014). Hence, ensuring that patients requesting
EAS are seen by two doctors has major resource implications that do not seem to have been comprehensively considered in EAS deliberations.

\section{Healthcare Professionals' Misconceptions About Limitation of Treatment and EAS}

It is not only patients who are confused about the nature and cause of dying - so are some doctors and other health professionals. A concern that treatment withdrawal is actually synonymous with euthanasia is at the root of some physicians' decisions to institute, escalate, and continue providing medical interventions even when they are of limited benefit (Goldstein et al., 2012). Confusion about what constitutes limitations or reductions of treatment; misunderstanding about comprehensive symptom control such as the use of opioids or sedation (Anquinet et al., 2013); and lack of clarity about the meaning of euthanasia can influence decisions. The following scenario further exemplifies this concern:

A man with end-stage respiratory disease and renal failure for which he was on dialysis stated his preferences for relief of dyspnea, including, after extensive discussion, his wish to receive opioids and to cease dialysis. The opioids proved effective, but his renal physician insisted he continue dialysis, challenging the use of opioids for dyspnea since "using opioids and ceasing dialysis were a form of euthanasia."

Such confusion has the potential to cause one to misconstrue the goals of care. Some have claimed that doctors are already practicing euthanasia but without scrutiny (Kuhse et al., 1997; White \& Willmott, 2012). The argument follows that current practices should be legitimized and made transparent through a relevant legislative framework. However, there is confusion, as some equate "the cessation of treatment or decisions not to treat when a person is dying . . . with giving a lethal injection to end a life" (Ashby, 1997). Such confusion does not take into account the irreversibility of the underlying condition, the potential for treatment futility given the clinical circumstances, and the safety of, for example, opioids as analgesics, even in high doses, when prescribed according to best palliative care practice. There is no evidence, when drugs are titrated carefully to achieve analgesia or symptom control, that life is shortened as a result. In fact, effective pain relief can actually prolong life by ensuring that patients do not die from the exhaustion associated with uncontrolled pain (Finlay, 2009).

Physicians may be reluctant to institute limits around medical treatments and symptom relief 
measures if they believe such practice is equivalent to EAS. Nevertheless, a decision to cease such lifesustaining treatment as dialysis requires thorough assessment of all contributing factors (Bostwick \& Cohen, 2009). The pragmatic distinction between ceasing treatment, instituting symptom relief measures (including sedation for refractory symptoms), and euthanasia is very clear-if the objective is achieved (namely, the burdensome treatment is ceased or the troublesome symptom relieved), that is where it stops. It appears that education is required to distinguish good medical decision making from an intention to end life (Finlay, 2009). We recognize that advocates of legalization of EAS may contend that greater clarity might ensue if EAS were to be implemented.

\section{Who Would Be Responsible for Performing EAS and What Would This Imply?}

Who would be the individuals or groups of healthcare professionals charged with the responsibility for enabling and enacting EAS? What training, supervision, scrutiny, and reporting of effective practice would be required for those teaching medical, nursing, and allied health students? How would this affect the training of clinicians in the care of seriously ill patients when it is already acknowledged that current health professionals' training does not adequately equip them for these roles (Noone, 2012)?

Distressing conditions such as depression affecting patients and their relatives are often unrecognized and so go untreated (Rayner et al., 2011; Mitchell, 2013). Skills in addressing the emotional, information, and support needs of patients are also lacking (Botti et al., 2006; Dilworth et al., 2014). What skills would be required in the context of EAS? Would health professionals be required to perform EAS before graduating? (Somerville, 2011). Would graduates potentially become desensitized? (Hendin \& Foley, 2008).

Responding to a request for EAS requires exquisite skills, judicious timing, and the capacity to engage in shared decision making. Without this confident, competent clinical judgment, the physician can never be satisfied that there really is no other reasonable solution for a patient's suffering (Hertogh et al., 2007; Snijdewind et al., 2014). These skills are neither commonplace nor included in existing curricula (Dees et al., 2013). In The Netherlands, the practice of EAS is not part of medical training and has ambiguous status: EAS is not considered "normal medical practice," but "extraordinary end-of-life care" entrusted-by law-to physicians.

Accordingly, if EAS were legalized, a wide-ranging review of all associated education curricula would be needed. Boudreau (2011) takes the discussion further by asking whether a new discipline- - "euthanatrics"- would of necessity arise.

What would be the nature of the assistance required in EAS? Doctors may be required by their personal ethical codes not to render assistance, even if the patient requests it. The important pragmatic issue here is whether certain roles would be prescribed within the EAS legislation, directing doctors how to respond to such a request (Kelly et al., 2004).

It is apparent that responding to requests for EAS has been difficult for some physicians who have felt unprepared and lacking in experience, especially when they did not know the patients very well (Dobscha et al., 2004; Hicks, 2006). Others (mainly General Practitioners) have felt unwilling to administer a lethal dose of medication, indicating that patients' access to a physician willing to respond to their request may be arbitrary (Sercu et al., 2012). Participating doctors in EAS found that it required a significant investment of time and was emotionally intense (Deschepper et al., 2014).

Some have argued that the impact of legalizing EAS will have dramatic effects on how medicine is perceived. Middleton (2012), for example, contends that to fundamentally change the role of the doctor as one who supports life to one who takes life will have profound, unpredictable effects on the perception and practice of medicine. This warrants further research. Still others have suggested that EAS is not necessarily the domain of medicine. Although legal requirements in most jurisdictions allowing EAS specify the physician's role, nurses in Switzerland are allowed to assist, and the physicians are not always present (Inghelbrecht et al., 2010). Some argue that administering a lethal medication does not necessarily require medical training (Randall \& Downie, 2010), while others assert that EAS needs to be medicalized as part of professional practice to ensure that the death is rapid and painless (Salem, 1999).

In a proposal from The Netherlands, supported by the Dutch Euthanasia Society and Society for Old Age Rational Suicide in the United Kingdom, assistance for "self-chosen death of the elderly" would be provided by counselors, removing it from the medical domain because it is an "existential problem" (Beekman, 2011). Meanwhile, in Oregon, a case has been made that assisted dying "need not be physician-assisted," thereby freeing doctors to focus on high-quality palliative care (Prokopetz \& Lehmann, 2012). It seems that some doctors continue to be reluctant to perform euthanasia; so help is offered to those whose "normal doctor" will not carry out the procedure (Patterson, 2012).

These issues highlight important questions that have largely been neglected about the potential 
impact on practitioners if the move to uphold self-determined and self-controlled death by way of condoning EAS were to be supported (Hertogh et al., 2007).

\section{The Issue of How Palliative Care and EAS Would "Interact"}

In the Northern Territory of Australia, where euthanasia was enacted from 1996 to 1997 (via the Rights of the Terminally Ill Act 1995 (NT)), guidelines required a palliative care consultation before a patient's request for euthanasia could be considered (Kissane et al., 1998). This potentially posed a considerable challenge for any palliative care physician responding to such a request. The goals of palliative care-including symptom relief, family support, assistance with decision making, and enhancing quality of life-are accomplished over time and within the context of supportive relationships. Through consultation with all members of the multidisciplinary team, patients and families are more likely to be adequately prepared to explore the psychological as well as physical symptoms. Multidisciplinary support replaces a "one-off" consultation, a salutary reminder that "quality end-of-life care is a dynamic process that is negotiated and renegotiated," and takes time (Steinhauser et al., 2000). In the Northern Territory, pressured by the new legislation and with the community's acquiescence, it seemed that a quick response was required, compromising opportunities for exploring the dying patient's psychosocial distress and suffering. All the tasks of palliative care were to be compressed (purportedly) into a single consultation-a seemingly impossible task, and not reflective of good practice. If EAS were to be legalized, it could potentially reduce the palliative care physician's role to mere tokenism in order to satisfy a patient's request to address a formality. Other deficiencies of this legislative approach were highlighted by the limited assessment and management of depression in the Northern Territory cases cited above (Kissane et al., 1998).

Should EAS be legalized, palliative care teams may need to determine whether and how it would be delivered within their services. If a particular palliative care service decided not to practice EAS, then decisions around referral pathways, the pragmatics for those patients too ill to travel to seek an alternative medical opinion, and many other considerations would require negotiation and potential additional resources.

The ethics of conscientious objection in medicine and nursing would also require careful discussion, recognizing that there may be differing views within the multidisciplinary team. If conscientious objection is considered a right for all health professionals, would this be automatically available in the context of EAS? While a full discussion on this issue is not possible here, it is important to note at least one distinctive view. Savulescu asserts that "doctors who compromise the delivery of medical services to patients on conscience grounds must be punished" (Savulescu, 2006). As well as erosion of trust in the doctor-patient relationship, trust between colleagues may also be compromised should the issue of conscientious objection be available but viewed differently within a therapeutic team. Furthermore, it may be difficult to distinguish between an EAS request that the doctor-all things considered-judges to be unjustified, and their conscientious objection.

\section{The Community Implications}

Community discussion of EAS has profound implications for palliative care when the latter is frequently identified as an antidote to EAS and therefore in opposition to euthanasia. Palliative care and euthanasia are perceived as responses to the same problem; that is, the suffering associated with dying. But one of the implications of legalizing EAS is that patients may feel compelled to choose whether they engage with palliative care or EAS.

If we truly want to advance the debate on EAS in more cogent and less emotional terms, palliative care needs to be accessible to all, without conditions. Hence, the challenge for palliative care is a publichealth one-to focus the debate on optimum care for people who are dying. Accordingly, if people wish to pursue EAS, this should not preclude their access to all that palliative care has to offer.

In the media discourse of people requesting EAS, it is sometimes claimed that the patient has "tried palliative care," the assumption being that EAS is the only alternative solution in response to such unrelieved suffering. In contrast to the palliative care team approach, well-meaning general physicians are too frequently ill equipped to address this suffering (Steinhauser et al., 2000). Acknowledging the profound and multifaceted nature of suffering in some situations, we believe that the broader community needs to be reassured of palliative care's significant role in attempting to relieve all aspects of suffering. Unrelieved distress is considered a palliative care emergency, prompting immediate attention (Palliative Care Expert Group, 2010). However, while the multidisciplinary palliative care team utilizes all their expertise and resources, they also acknowledge that some aspects of pain and suffering cannot not be completely ameliorated (Noble. 2013).

Despite the proven benefits of palliative care and policy recommendations supporting its widespread availability (de Lima et al., 2012), there is inequity 
and inconsistency in the provision of end-of-life care in Australia (Palliative Care Australia, 2012) and in many other countries (World Health Organization, 2014). While the overwhelming majority of healthy Australians nominate home as their preferred place to die, $52 \%$ actually die in hospital (Australian Commission on Safety and Quality in Health Care (ACSQHC) 2013). There they frequently receive high-cost interventions delivered contrary to bestavailable evidence, and sometimes without fully informed decision making from the individual and/or their family carers (Palliative Care Australia, 2008). In this setting, disregarding the wishes of patients and their carers results in a high cost burden for the health system and potentially a poorer quality of death (Department of Health and Ageing, 2010).

The lack of equal access for people who require palliative care is sobering, with Palliative Care Australia contending that it is "nothing short of a lottery," dependent on location, diagnosis, cultural background, age, and health professionals' education (Palliative Care Australia, 2011a,b). Meanwhile, in the United Kingdom, hospice care has been referred to as "heaven for a few" (Clark et al., 2005). Despite government commitment and the dedication of health professionals, carers, and volunteers, many continue to miss out on appropriate end-of-life care. Bereavement care (a core tenet of palliative care) is also currently suboptimal, as is the availability of palliative care in rural areas (Hudson, 2013).

Like most health issues, the reasons for these anomalies are complex: inadequate funding, insufficient training of health professionals, lack of culturally appropriate resources and services, societal unwillingness to accept and openly discuss dying, and our rapidly aging population (Palliative Care Australia, 2011a,b). It is also essential to make the case for every person's right to access adequate pain relief and their right to refuse all medical treatment, including artificial hydration and nutrition (Hendin \& Foley, 2008).

EAS requests are uncommon. Approximately 50,000 palliative care patients are admitted to Australian hospitals each year (Palliative Care Australia, 2011a,b). Less than $1 \%$ of those with advanced illness referred to hospital palliative care services have a sustained desire for EAS (unpublished data, JP). A prospective study in seven palliative care units in France over a 6-month period similarly reported a rather low frequency of requests for euthanasia (13 of 611 patients or $2.1 \%$ ) (Comby \& Filbert, 2005). Rates are also low for people who have availed themselves of EAS in jurisdictions where it is supported: $0.22 \%$ per 10,000 deaths in Oregon and less than 2.8\% of all deaths in The Netherlands (Oregon Health Authority, 2014b; Snijdewind et al., 2014). Despite these low rates, requests and statements regarding a desire to die and EAS need a competent and compassionate response. While preliminary work on guidelines to respond to desire-for-death requests has been undertaken, training and research in this area is urgently needed (Hudson et al., 2006).

Investment in palliative care is likely to have a much greater population impact than investment in facilitating widely available legal EAS. Given the small numbers of people facing advanced illness who actually desire EAS, it seems logical that priority be given to resource and policy perspectives necessary for educating all health professionals about palliative care rather than directing resources at this time to giving legal status to EAS. Currently, palliative care is not mandated in undergraduate curricula, yet every healthcare professional will be required to care for a dying patient and family. Undue emphasis on EAS is misplaced for the vast majority of Australians facing a terminal illness, who seemingly have a low interest in EAS and may currently miss out on the benefits of palliative care provision.

Legalizing EAS would have practical implications for palliative care's commitment to making such care available for all Australians. For example, a focus on establishing "networks of care that allow patients to access appropriate and timely care consistent with their level of need" (Department of Health and Ageing, 2005) has the potential to increase society's confidence in end-of-life care. Public attention directed toward EAS at this point in time may detract from this aim.

Networks of care include support for family carers, whose needs for psychological care and relevant information are at present largely unmet (Hudson \& Payne, 2011). While the psychological outcomes of bereaved family members are better for those who access palliative care services (Hudson \& Payne, 2011), the outcomes for those family members of patients who have undergone EAS require much more empirical inquiry (Ganzini et al., 2009; Wagner et al., 2012). For example, higher instances of posttraumatic distress disorder and depression in families who have witnessed EAS have been reported (Wagner et al., 2012). The longer-term impact on health professionals remains largely unknown.

It is also apparent that the views of relatives/family carers can influence doctors' decision making in response to EAS requests. This interface has been largely overlooked, and the role that family carers undertake in the process of EAS is underexplored (Snijdewind et al., 2014).

The role of psychiatry in decision making for those requesting to end their lives also needs increased focus, including the need to ensure appropriate 
training in assessment (Macleod et al., 2012) and therapeutic communication (Kelly et al., 2003).

Economic factors may become a very real issue. In some instances in Oregon, health insurance covers inexpensive lethal drugs for EAS, but not the costly drugs used in palliative care. A routine letter is sent to patients with a prognosis of around five years, offering them full payment for "assisted suicide (euphemistically categorized as 'comfort care,' thereby further blurring the boundaries between palliative care and EAS)" (Marker, 2008). Patients who choose EAS to avoid being a burden on carers may be influenced by the cost of care, and palliative care specialists would be obliged to discuss these options.

In contemporary healthcare, before implementing any new initiative, it is expected that a suitable evidence base be ensured and that associated costs and ongoing evaluation factored in, criteria that seem to be unmet in relation to EAS. Consideration also needs to be given to the costs of comprehensive monitoring and reporting of EAS (Hendin \& Foley, 2008).

Awareness raising and capacity building pertaining to these issues coincide with the aims of palliative care, requiring urgent public-health changes to enable each person with a life-threatening illness, their family, and carers to have access to well-resourced quality palliative care (Australian Institute of Health and Welfare, 2011). We need to promote natural death, avoid unnecessarily prolonging the dying process (Somerville, 2011), and base our practice on the World Health Organization (WHO) (2002) definition of palliative care, which affirms life, regards dying as a normal process, and intends neither to hasten nor postpone death.

\section{CONCLUSIONS}

The overwhelming majority of justifications for EAS focus on the individual who desires this pathway, while the potential impact on society, institutions, and healthcare delivery have received far less attention (Somerville, 2011). We believe that most discussion around EAS and its place in the care of those with advanced illness is conducted in an environment far from the bedside, and removed from the experiences of those with the illness, their carers, and the palliative care health professionals who deliver end-of-life care on a daily basis. In this paper, we have provided insights from our experiences, coupled with those from various jurisdictions where EAS is, or was, legalized, to highlight what we believe are pragmatic implications for palliative care services should EAS be legalized in Australia. We believe that these issues, many of which are encountered at the bedside, must be considered in detail. Increased resources and effort must be directed toward training, research, community engagement, and ensuring adequate resourcing for palliative care to benefit many before further consideration is given to allocating resources into legalizing EAS to respond to the requests of a few.

\section{REFERENCES}

Anquinet, L., Raus, K., Sterckx, S., et al. (2013). Similarities and differences between continuous sedation until death and euthanasia: Professional caregivers' attitudes and experiences: A focus group study. Palliative Medicine, 27(6), 553-561.

Ashby, M. (1997). The fallacies of death causation in palliative care. The Medical Journal of Australia, 166(4), 176-177.

Australian Commission on Safety and Quality in Health Care (ACSQHC) (2013). Safety and quality of end-oflife care in acute hospitals: A background paper. Sydney: Australian Commission on Safety and Quality in Health Care. Available from http://www.safetyandquality.gov. $\mathrm{au} / \mathrm{wp}$-content/uploads/2013/09/SAQ083_End_of_life_ care_V15_FILM_REVISED_TAGGED.pdf.

Australian Institute of Health and Welfare (AIHW) (2011). Trends in palliative care in Australian hospitals. Canberra: The Australian Institute of Health and Welfare. Available from http://www.aihw.gov.au/publicationdetail/?id=10737420167. Last accessed January 17, 2015.

Beekman, W. (2011). ojThe self-chosen death of the elderly. Available from http://farewellfoundation.ca/wordpress/ wp-content/uploads/2011/08/self-chosen-death-of-theelderly.pdf.

Bostwick, J.M. \& Cohen, L.M. (2009). Differentiating suicide from life-ending acts and end-of-life decisions: A model based on chronic kidney disease and dialysis. Psychosomatics, 50(1), 1-7.

Botti, M., Endacott, R., Watts, R., et al. (2006). Barriers in providing psychosocial support for patients with cancer. Cancer Nursing, 29(4), 309-316.

Boudreau, J.D. (2011). Physician-assisted suicide and euthanasia: Can you even imagine teaching medical students how to end their patients' lives? The Permanente Journal, 15(4), 79-84.

Clark, D., Small, N., Wright, M., et al. (2005). A bit of heaven for the few? Lancaster, England: Observatory Publications.

Comby, M.C. \& Filbert, M. (2005). The demand for euthanasia in palliative care units: A prospective study in seven units of the "Rhône-Alpes" region. Palliative Medicine, 19, 587-593.

Davies, N., Maio, L., van Riet Paap, J., et al. (2014). Quality palliative care for cancer and dementia in five European countries: Some common challenges. Aging \& Mental Health, 18(4), 400-410.

de Lima, L., Bennett, M.I., Hudson, P., et al. (2012). International Association for Hospice and Palliative Care (IAHPC) list of essential practices in palliative care. Journal of Pain \& Palliative Care Pharmacotherapy, 26(2), 118-122.

Dees, M.K., Vernooij-Dassen, M.J., Dekkers, W.J., et al. (2013). Perspectives of decision-making in requests for euthanasia: A qualitative research among patients, 
relatives and treating physicians in The Netherlands. Palliative Medicine, 27(1), 27-37.

Department of Health and Ageing (2005). National palliative care strategy: Activity implementation report. Canberra: DoHA.

Department of Health and Ageing (2010). Update national palliative care strategy: Phase 1 report. Version 2.0. Canberra: DoHA. Available from http://www.reindex.org/ $\mathrm{PAVI} / \mathrm{main} /$ Hits.php?qe $=\mathrm{lfo}=\% 22$ Department $\% 200 \mathrm{f} \% 20$ Health\%22\&focus $=1055$.

Deschepper, R., Distelmans, W. \& Bilsen, J. (2014). Requests for euthanasia/physician-assisted suicide on the basis of mental suffering: Vulnerable patients or vulnerable physicians? JAMA Psychiatry, 71(6), 617-618.

Detering, K.M., Hancock, A.D., Reade, M.D., et al. (2010). The impact of advance care planning on end of life care in elderly patients: Randomized controlled trial. BMJ, 340, c1345. Available from http://www.bmj.com/ content/340/bmj.c1345.

Dilworth, S., Higgins, I., Parker, V., et al. (2014). Patient and health professional's perceived barriers to the delivery of psychosocial care to adults with cancer: A systematic review. Psycho-Oncology, 23(6), 601-612.

Dobscha, S.K., Heintz, R.T., Press, N., et al. (2004). Oregon physicians' responses to requests for assisted suicide: A qualitative study. Journal of Palliative Medicine, 7(3), $451-461$.

Doyle, D. (2003). The world of palliative care: One man's view. Journal of Palliative Care, 19, 149-158.

Finlay, I. (2009). The art of medicine: Dying and choosing. Lancet, 373, 1840-1841.

Frost, T.D., Sinha, D. \& Gilbert, B.J. (2014). Should assisted dying be legalized? Philosophy, Ethics, and Humanities in Medicine, 9(1), 3. Available from http://www. peh-med.com/content/9/1/3.

Ganzini, L., Goy, E.R., Dobscha, S.K., et al. (2009). Mental health outcomes of family members of Oregonians who request physician aid in dying. Journal of Pain and Symptom Management, 38(6), 807-815.

George, R., Finlay, I. \& Jeffrey, D. (2005). Taking the final step: Changing the law on euthanasia and physician-assisted suicide. Legalised euthanasia will violate the rights of vulnerable patients. BMJ, 331(7518), 684 .

Glare, P., Sinclair, C., Downing, M., et al. (2008). Predicting survival in patients with advanced disease. European Journal of Cancer, 44(8), 1146-1156.

Goldstein, N.E., Cohen, L.M., Arnold, R.M., et al. (2012). Prevalence of formal accusations of murder and euthanasia against physicians. Journal of Palliative Medicine, 15(3), 334-339.

Hendin, H. \& Foley, K. (2008). Physician-assisted suicide in Oregon: A medical perspective. Michigan Law Review, 106(8), 1613-1640.

Hendry, M., Pasterfield, D., Lewis, R., et al. (2013). Why do we want the right to die? A systematic review of the international literature on the views of patients, carers and the public on assisted dying. Palliative Medicine, $27(1), 13-26$.

Hertogh, C.M., de Boer, M.E., Dröes, R.M., et al. (2007). Would we rather lose our life than lose our self? Lessons from the Dutch debate on euthanasia for patients with dementia. The American Journal of Bioethics, 7(4), 48-56.

Hicks, M.H. (2006). Physician-assisted suicide: A review of the literature concerning practical and clinical implications for UK doctors. BMC Family Practice, 7(1), 39.
Hudson, P. (2004). Positive aspects and challenges associated with caring for a dying relative at home. International Journal of Palliative Nursing, 10(2), 58-65; discussion 65.

Hudson, P. (2013). Improving support for family carers: Key implications for research, policy and practice. Palliative Medicine, 27(7), 581-582.

Hudson, P. \& Payne, S. (2011). Family caregivers and palliative care: Current status and agenda for the future. Journal of Palliative Medicine, 14(7), 864-869.

Hudson, P., Schofield, P., Kelly, B., et al. (2006). Responding to desire to die statements from patients with advanced disease: Recommendations for health professionals. Palliative Medicine, 20(7), 703-710.

Hudson, P., Remedios, C., Zordan, R., et al. (2012). Guidelines for the psychosocial and bereavement support of family caregivers of palliative care patients. Journal of Palliative Medicine, 15(6), 696-702.

Inghelbrecht, E., Bilsen, J., Mortier, F., et al. (2010). The role of nurses in physician-assisted deaths in Belgium. CMAJ, 182(9), 905-910.

Johnson, C., Paul, C., Girgis, A., et al. (2011). Australian general practitioners' and oncology specialists' perceptions of barriers and facilitators of access to specialist palliative care services. Journal of Palliative Medicine, 14(4), 429-435.

Kelly, B.J. \& Varghese, F.T. (1996). Assisted suicide and euthanasia: What about the clinical issues? The Australian and New Zealand Journal of Psychiatry, 30(1), 3-8.

Kelly, B., Burnett, P., Pelusi, D., et al. (2003). Factors associated with the wish to hasten death: A study of patients with terminal illness. Psychological Medicine, 33, $75-81$.

Kelly, B.J., Burnett, P., Pelusi, D., et al. (2004). Association between clinician factors and a patient's wish to hasten death: Terminally ill cancer patients and their doctors. Psychosomatics, 45(4), 311-318.

Kissane, D.W., Street, A. \& Nitschke, P. (1998). Seven deaths in Darwin: Case studies under the Rights of the Terminally Ill Act, Northern Territory, Australia. Lancet, 352(9134), 1097-1102.

Kuhse, H., Singer, P., Baume, P., et al. (1997). End-of-life decisions in Australian medical practice. The Medical Journal of Australia, 166(4), 191-196.

Kwon, J.H. (2014). Overcoming barriers in cancer pain management. Journal of Clinical Oncology, 32(16), 1727-1733.

Levene, I. \& Parker, M. (2011). Prevalence of depression in granted and refused requests for euthanasia and assisted suicide: A systematic review. Journal of Medical Ethics, 37(4), 205-211.

Mack, J.W., Cronin, A. Keating, N.L., et al. (2012). Associations between end-of-life discussion characteristics and care received near death: A prospective cohort study. Journal of Clinical Oncology, 30(35), 4387-4395.

Macleod, R.D., Wilson, D.M. \& Malpas, P. (2012). Assisted or hastened death: The healthcare practitioner's dilemma. Global Journal of Health Science, 4(6), 87-98.

Marker, R.L. (2008). Oregon's suicidal approach to healthcare. American Thinker, Available from http://www. americanthinker.com/articles/2008/09/oregons_suicidal_ approach_to_h.html. Last accessed January 17, 2015.

Middleton, C. (2012). Why is euthanasia illegal in Australia? ABC The World Today. Available from http://www. abc.net.au/worldtoday/content/2012. Last accessed March 14, 2013. 
Mitchell, A.J. (2013). Screening for cancer-related distress: When is implementation successful and when is it unsuccessful? Acta Oncologica, 52(2), 216-224.

Noble, B. (2013). Legalising assisted dying puts vulnerable patients at risk and doctors must speak up. BMJ, 346, f4062.

Noone, Y. (2012). There's no need to suffer in silence. Australian Ageing Agenda. Available from http://www. australianageingagenda.com.au/2012/02/03/theres-noneed-to-suffer-in-silence/. Last accessed December 17, 2013.

Oldham, R.L., Dobscha, S.K., Goy, E.R., et al. (2011). Attachment styles of Oregonians who request physician-assisted death. Palliative \& Supportive Care, 9(02), 123-128.

Oregon Health Authority (2014a). Oregon's Death with Dignity Act. Available from http://public.health.oregon. gov/ProviderPartnerResources/EvaluationResearch/ DeathwithDignityAct/Pages/index.aspx. Last accessed January 15, 2015.

Oregon Health Authority (2014b). Oregon's Death with Dignity Act-Resources. Available from http://public. health.oregon.gov/ProviderPartnerResources/Evaluation Research/DeathwithDignityAct/Documents/year16.pdf. Last accessed February 2, 2015.

Palliative Care Australia (2005). Standards for providing quality palliative care for all Australians. Canberra: Palliative Care Australia. Available from http://www. palliativecare.org.au/Portals/46/Standards\%20for $\% 20$ providing $\% 20$ quality $\% 20$ palliative $\% 20$ care $\% 20$ for $\% 20$ all\%20Australians.pdf. Last accessed January 17, 2015.

Palliative Care Australia (2008). A matter of life and death: Confronting the new reality. Report of outcomes. Canberra: Palliative Care Australia.

Palliative Care Australia (2011a). National palliative care consensus statement and call to action. Canberra: Palliative Care Australia. Available from http://www. palliativecare.org.au/Portals/46/Palliative_Care_ Consensus_Statement_final.pdf. Last accessed January 17, 2015.

Palliative Care Australia (2011b). Submission to the Australian Senate Standing Committee on Community Affairs Inquiry into palliative care in Australia. Canberra: Palliative Care Australia. Available from http:// www.palliativecare.org.au/Portals/46/Policy/Submissions $\% 20$ and \%20reports/PCA\%27s\%20Submission\%20to\%20 Senate $\% 20$ Inquiry $\% 20$ into $\% 20$ Palliative $\% 20$ Care $\% 20$ in\%20Australia\%20Final.pdf. Last accessed January 17, 2015.

Palliative Care Australia (2012). End-of-life care is everyone's affair: Tackling the challenge of "end of life." Canberra: Palliative Care Australia. Available from http:// www.palliativecare.org.au/Portals/46/PCA\%20submission \%20to\%20NHHRC.pdf. Last accessed January 17, 2015.

Palliative Care Expert Group (2010). Therapeutic guidelines: Palliative care. Version 3. Melbourne: Therapeutic Guidelines Ltd.

Patterson, T. (2012). Euthanasia squads offer death by delivery. The Independent, March 2. Available from http://www.independent.co.uk/life-style/health-andfamilies/health-news/euthanasia-squads-offer-deathby-delivery-7469070.html. Last accessed January 17, 2015.

Pellegrino, E.D. (2001). Physician-assisted suicide and euthanasia: Rebuttals of rebuttals. The moral prohibition remains. The Journal of Medicine and Philosophy, 26(1), 93-100.
Pereira, J. (2011). Legalizing euthanasia or assisted suicide: The illusion of safeguards and controls. Current Oncology, 18(2), e38.

Price, A., McCormack, R., Wiseman, T., et al. (2014). Concepts of mental capacity for patients requesting assisted suicide: A qualitative analysis of expert evidence presented to the Commission on Assisted Dying. BMC Medical Ethics, 15(1), 32.

Prokopetz, J.J. \& Lehmann, L.S. (2012). Redefining physicians' role in assisted dying. The New England Journal of Medicine, 367(2), 97-99.

Randall, F. \& Downie, R.S. (2010). End-of-life choices: Consensus and controversy. New York, Oxford University Press.

Rayner, L., Lee, W., Price, A., et al. (2011). The clinical epidemiology of depression in palliative care and the predictive value of somatic symptoms: Cross-sectional survey with four-week follow-up. Palliative Medicine, 25(3), 229-241.

Reid, C., Gooberman-Hill, R. \& Hanks, G. (2008). Opioid analgesics for cancer pain: Symptom control for the living or comfort for the dying? A qualitative study to investigate the factors influencing the decision to accept morphine for pain caused by cancer. Annals of Oncology, $19(1), 44-48$.

Rubeli, E. (2012). What happened to going out in style? The Global Mail. Available from http://www.theglobalmail. org/feature/what-happened-to-going-out-in-style/507/ . Last accessed January 17, 2015.

Salem, T. (1999). Physician-assisted suicide. Promoting autonomy-or medicalizing suicide? The Hastings Center Report, 29(3), 30-36.

Savulescu, J. (2006). Conscientious objection in medicine. BMJ, 332(7536), 294-297.

Sercu, M., Pype, P., Christiaens, T., et al. (2012). Are general practitioners prepared to end life on request in a country where euthanasia is legalised? Journal of Medical Ethics, 38(5), 274-280.

Snijdewind, M.C., van Tol, D.G., Onwuteaka-Philipsen, B.D., et al. (2014). Complexities in euthanasia or physician-assisted suicide as perceived by Dutch physicians and patients' relatives. Journal of Pain and Symptom Management, 48(6), 1125-1134.

Somerville, M. (2011). Euthanasia: Is legalizing it a good idea? Australian Dialogues, pp. 17-19. Montreal: McGill University.

Steinhauser, K.E., Christakis, N.A., Clipp, E.C., et al. (2000). Factors considered important at the end of life by patients, family, physicians, and other care providers. The Journal of the American Medical Association, 284(19), 2476-2482.

Volicer, L. (2008). End-of-life care for people with dementia in long-term care settings. Alzheimer's Care Today, 9(2), 84-102. Available from http://www.iagg.info/data/ VOLICER_-_End_of_life_care_in_Dementia_1.pdf. Lasts accessed January 17, 2015.

Wagner, B., Muller, J. \& Maercker, A. (2012). Death by request in Switzerland: Posttraumatic stress disorder and complicated grief after witnessing assisted suicide. European Psychiatry, 27(7), 542-546.

White, B. \& Willmott, L. (2012). A background paper. How should Australia regulate voluntary euthanasia and assisted suicide? Weston: Australia21 Limited.

White, B.P., Willmott, L. \& Ashby, M. (2011). Palliative care, double effect and the law in Australia. Internal Medicine Journal, 41(6), 485-492. 
Wong, W.K.T., Ussher, J.M. \& Perz, J. (2009). Strength through adversity: Bereaved cancer carers' accounts of rewards and personal growth from caring. Palliative \& Supportive Care, 7, 187-196.

World Health Organization (2002). National cancer control programmes: Policies and managerial guidelines, 2nd ed. Geneva: WHO. Available from http://www.who. int/cancer/media/en/408.pdf. Last accessed January $17,2015$.

World Health Organization (2014). Global atlas of palliative care at the end of life. Geneva: WHO. Available from http://www.who.int/nmh/Global_ Atlas_of_Palliative_Care.pdf. Last accessed January $17,2015$. 